\title{
Removal of tyrosol from water by adsorption on carbonaceous materials and electrochemical advanced oxidation processes
}

\author{
Nelly Flores ${ }^{\mathrm{a}}$, Farbod Sharif ${ }^{\mathrm{b}}$, Nael Yasri ${ }^{\mathrm{b}}$, Enric Brillas ${ }^{\mathrm{a}}$, Ignasi Sirés ${ }^{\mathrm{a}, *}$, Edward P.L. Roberts $^{\mathrm{b}, * *}$ \\ a Laboratori d'Electroquímica dels Materials i del Medi Ambient, Departament de Química Física, Facultat de Química, Universitat de Barcelona, Martí i Franquès 1-11, 08028 \\ Barcelona, Spain \\ ${ }^{\mathrm{b}}$ University of Calgary, Department of Chemical and Petroleum Engineering, 2500 University Drive NW, Calgary, AB T2N $1 N 4$, Canada
}

\section{A R T I C L E IN F O}

Article history:

Received 30 January 2018

Received in revised form 27 February 2018

Accepted 4 March 2018

Available online $\mathrm{xxx}$

Keywords:

Adsorption

Electrochemical oxidation

Electrochemical regeneration

Graphene

Photoelectro-Fenton

Tyrosol

\begin{abstract}
A B S T R A C T
This work compares the ability of physical and chemical treatments, namely adsorption and electrochemical advanced oxidation processes, to remove tyrosol from aqueous medium. Adsorption on graphene nanoplatelets (GNPs) performed much better than a graphite intercalation compound. Adsorption isotherm fit with Freundlich model $\left(R^{2}=0.96\right)$, which is characteristic of a chemisorption process. Successful electrochemical regeneration enables 5 successive adsorption/regeneration cycles before corrosion of GNPs occurs. Other typical aromatic contaminants that may coexist with tyrosol can be also adsorbed on GNPs. Percentage of regeneration efficiency of GNPs showed a higher affinity towards Lewis acids group compounds and a lower one towards Lewis base. The treatment of $100 \mathrm{~mL}$ of $0.723 \mathrm{mM}$ tyrosol solutions in non-chlorinated and chlorinated matrices at $\mathrm{pH} 3.0$ was carried out by electrochemical oxidation with electrogenerated $\mathrm{H}_{2} \mathrm{O}_{2}$ $\left(\mathrm{EO}-\mathrm{H}_{2} \mathrm{O}_{2}\right)$, electro-Fenton (EF) and UVA photoelectro-Fenton (PEF). Trials were made with a BDD anode and an air-diffusion cathode at $10-30 \mathrm{~mA} \mathrm{~cm}^{-2}$. Hydroxyl radicals formed at the anode from water oxidation and/or in the bulk from Fenton's reaction between added $\mathrm{Fe}^{2+}$ and generated $\mathrm{H}_{2} \mathrm{O}_{2}$, along with active chlorine produced in chlorinated medium, were the main oxidants. Tyrosol concentration always decayed following a pseudo-first-order kinetics and its mineralization rose as EO- $\mathrm{H}_{2} \mathrm{O}_{2}<\mathrm{EF}<\mathrm{PEF}$, more rapidly in the chlorinated matrix. The potent photolysis of intermediates under UVA radiation explained the almost total mineralization achieved by PEF in the latter medium. The effect of current density and tyrosol content on the performance of all processes was examined.
\end{abstract}

\section{Introduction}

Olive oil production is very important for the agroeconomy in the Mediterranean basin countries, from north Africa to eastern Asia and southern Europe (Roig et al., 2006). Olive oil processing involves mechanical pressure or centrifugation, which generate a large amount of effluent, estimated to be more than 30 million cubic meters annually (Dermeche et al., 2013; Magdich et al., 2013). As a result, there is great concern in the respective countries about the processing of olive oil in mills. Olive oil mill wastewater (OMWW) causes a significant environmental impact because of its high organic load and turbidity, thereby causing poor light penetration and consumption of dissolved oxygen in water bodies where it is discharged. OMWW is typically characterized by high chemical oxygen demand (COD) and total solids content, up to 110 and $150 \mathrm{gL}^{-1}$, respectively. Furthermore, recalcitrant components such as tannins, sugars, lipids and phenols can account for up to $37 \%$ of the total mass of organics in OMWW (DellaGreca et al., 2004; Ochando-Pulido et al., 2014). Other organic

\footnotetext{
* Corresponding author.

** Corresponding author.

Email addresses: i.sires@ub.edu (I. Sirés); edward.roberts@ucalgary.ca (E.P.L. Roberts)
}

compounds present in OMWW can include polyphenols, polyalcohols, and pectins (Justino et al., 2012). The chemical composition of OMWW is fairly consistent, but the concentrations of contaminants can vary from one region to another (Allouche et al., 2004).

It is necessary that phenolic compounds of low molecular weight are efficiently removed from wastewater, since they are more mobile, toxic for bacteria (Yesilada et al., 1997) and aquatic organisms (Fiorentino et al., 2003), and they also inhibit seed germination (Aliotta et al., 2002). A major component of the phenolic fraction of OMWW is tyrosol (4-hydroxyphenylethanol), and its derivatives trans-cinnamic acid (TCA), trans-ferulic acid (TFA), and 4-hydroxyphenylacetic acid (HPA) (Allouche et al., 2004). The tyrosol content in OMWW may reach up to $25 \mathrm{gL}^{-1}$ (McNamara et al., 2008). The recovery of antioxidant phenolic compounds from OMWW and solid wastes has been proposed as a source of biologically active polyphenols (Capasso et al., 1999; Fernández-Bolaños et al., 2002; Khoufi et al., 2008; Ben Abdallah et al., 2017).

Adsorption is an attractive technology for OMWW treatment to fulfill two goals: water decontamination and recovery of added-value chemicals (Ena et al., 2012). Carbonaceous materials are the preferred adsorbents, due to their moderate cost, high affinity towards most organic adsorbates, and easy regeneration. Among them, the prolific use of activated carbon is well known. For electrochemical 
regeneration, issues related to long adsorption and regeneration times associated with the porous structure of activated carbon (Narbaitz and Cen, 1994; Hussain et al., 2013), have led to the emergence of other adsorbent materials. Micrometer-sized particles of non-porous unexpanded graphite intercalation compound (GIC) have been shown to remove dyes (Brown et al., 2004b; Nkrumah-Amoako et al., 2014), pesticides (Brown et al., 2004a) and phenols (Brown and Roberts, 2007; Hussain et al., 2013). This material has also been found to be suitable for efficient electrochemical regeneration, and regeneration efficiencies of $100 \%$ have been demonstrated (Ashgar et al., 2012). This regeneration method is advantageous compared to thermal, chemical or wet air approaches, in terms of quality, cost, simplicity and environmental impact (Berenguer et al., 2010). Alternatively, nanoengineered carbon-based adsorbents like fullerenes and carbon nanotubes have gained attention owing to their much larger surface area that may enhance the adsorption capacity (Yang and Xing, 2010). Graphene and its derivatives are also very promising owing to their larger surface area and high electrical conductivity (Wang et al., 2012; Sharif et al., 2017) and, among them, graphene nanosheets (GNS) are being developed as next-generation adsorbents due to their high adsorption capacity along with their affinity toward organic contaminants (Ersan et al., 2017). Previous studies about tyrosol adsorption on carbonaceous substrates have focused on conventional activated carbon materials such as active charcoal (Richard et al., 2010). Hence, it is necessary to investigate the performance of some of the newest advanced adsorbents mentioned.

Electrochemical advanced oxidation processes (EAOPs) such as electrochemical oxidation with $\mathrm{H}_{2} \mathrm{O}_{2}\left(\mathrm{EO}-\mathrm{H}_{2} \mathrm{O}_{2}\right)$, electro-Fenton (EF) and photoelectro-Fenton (PEF) are powerful transformation technologies for wastewater treatment (Feng et al., 2013; Sirés et al., 2014; Vasudevan and Oturan, 2014; Moreira et al., 2017; Yasri and Gunasekaran, 2017). The oxidation power of these methods depends on the anode, with boron-doped diamond (BDD) emerging as one of the best options for the treatment of refractory organic pollutants (Marselli et al., 2003; Panizza and Cerisola, 2009; Coria et al., 2016; Steter et al. 2016). In an undivided cell, physisorbed hydroxyl radical $(\mathrm{BDD}(\mathrm{OH}))$ is formed as main oxidant on BDD from anodic water oxidation via reaction (1). EF and PEF operate at an optimal $\mathrm{pH}$ of around 3, where the generation of free $\mathrm{OH}$ occurs simultaneously in the bulk from Fenton's reaction (2) between added $\mathrm{Fe}^{2+}$ and $\mathrm{H}_{2} \mathrm{O}_{2}$ electrogenerated at the cathode (Galia et al., 2016; Flores et al., $2017 \mathrm{~b}$ ). The use of UVA light to irradiate the solution induces the larger accumulation of ${ }^{\circ} \mathrm{OH}$ owing to photolysis of $\mathrm{Fe}(\mathrm{OH})^{2+}$ from reaction (3) and the photodegradation of photosensitive intermediates like $\mathrm{Fe}(\mathrm{III})$-carboxylate complexes via reaction (4) (El-Ghenymy et al., 2013; Olvera-Vargas et al., 2015; Yasri and Gunasekaran, 2017).

$$
\begin{aligned}
& \mathrm{BDD}+\mathrm{H}_{2} \mathrm{O} \rightarrow \mathrm{BDD}\left({ }^{\bullet} \mathrm{OH}\right)+\mathrm{H}^{+}+\mathrm{e}^{-} \\
& \mathrm{H}_{2} \mathrm{O}_{2}+\mathrm{Fe}^{2+} \rightarrow \mathrm{Fe}^{3+}+{ }^{\cdot} \mathrm{OH}+\mathrm{OH}^{-} \\
& \mathrm{Fe}(\mathrm{OH})^{2+}+h v \rightarrow \mathrm{Fe}^{2+}+\cdot{ }^{\cdot} \mathrm{OH} \\
& \mathrm{Fe}(\mathrm{OOCR})^{2+}+h v \rightarrow \mathrm{Fe}^{2+}+\mathrm{CO}_{2}+\mathrm{R}^{\bullet}
\end{aligned}
$$

The effectiveness of these EAOPs has been demonstrated for the degradation of components of OMWW such as TCA (E-3-phenyl-2-propenoic acid) (Flores et al., 2017b) and the phenolic compounds TFA (4-hydroxy-3-methoxycinnamic acid) (Flores et

$$
\text { al., }
$$

HPA (Flores et al., 2017a). However, less is known about their effectiveness for treating tyrosol solutions. In $\mathrm{EO}$ with $\mathrm{PbO}_{2}$ or BDD anodes (Gargouri et al., 2017) and conventional EF with a Pt anode (Ben Abdallah et al., 2017), tyrosol was transformed into hydroxytyrosol, whereas up to $90 \%$ mineralization was feasible by heterogeneous EF treatment with a BDD anode, carbon felt cathode and pyrite as catalyst (Ammar et al., 2015).

This work aims to study the decontamination of synthetic tyrosol solutions by adsorption and several EAOPs. Adsorption was investigated with GIC and exfoliated graphene as adsorbents, and the results of the latter material were compared with those obtained for other OMWW components including acids like TCA, TFA and HPA, as well as phenol as a model pollutant. In tests performed with graphene, the adsorbent was electrochemically regenerated to show its potential reuse. Moreover, tyrosol solutions were comparatively degraded by EO- $\mathrm{H}_{2} \mathrm{O}_{2}, \mathrm{EF}$ and PEF in the absence and presence of $\mathrm{Cl}^{-}$ion. The effect of operating parameters such as current density $(j)$ and tyrosol concentration on the pollutant and total organic carbon (TOC) decays was examined.

\section{Experimental}

\subsection{Chemicals and materials}

The following reagent grade chemicals were used as received: Tyrosol (98\% purity) from Alfa Aesar, and TCA ( $>99 \%$ purity), TFA (99\% purity), HPA ( $98 \%$ purity) and phenol ( $>99 \%$ purity) from Sigma-Aldrich. Fig. SM-1 shows the structural formula of these five contaminants. Other chemicals, organic solvents and salts employed were of HPLC or analytical grade purchased from BDH, Fluka, Merck, Probus and Sigma-Aldrich. Ultrapure water (Millipore Milli-Q system, resistivity $>18.2 \mathrm{M} \Omega \mathrm{cm}$ ) was used to prepare all synthetic solutions.

Two carbonaceous adsorbents were used: (i) unexpanded GIC Nyex ${ }^{\mathrm{TM}} 1000$ from Arvia Technology Ltd, as graphitic flakes with $98 \%$ carbon content, $484 \mu \mathrm{m}$ diameter and non-porous, i.e., with no internal surface according to mercury porosimetry (Hussain et al., 2013), and (ii) graphene nanoplatelets (GNPs), xGNP-M-25 from XG Sciences, with $120-150 \mathrm{~m}^{2} \mathrm{~g}^{-1}$ surface area, $6 \mathrm{~nm}$ average thickness and $25 \mu \mathrm{m}$ particle diameters. Note that GNPs are comprised of short stacks of platelet-shaped graphene sheets, and are considered a form of GNS.

\subsection{Adsorption assays}

Adsorption experiments were performed in a batch mode with $100 \mathrm{~mL}$ of suspension containing $100 \mathrm{mg} \mathrm{L}^{-1}$ of contaminant mixed with a known quantity of adsorbent (usually $10 \mathrm{~g} \mathrm{~L}^{-1}$ of GNPs or $100 \mathrm{~g}$ $\mathrm{L}^{-1}$ of GIC) at $\mathrm{pH}=7.5$ (or otherwise stated) using an orbital shaker (VWR 3500) until equilibrium was attained. Contaminants studied in this work are TCA, TFA, HPA, tyrosol and phenol. Adsorption isotherms were determined for different quantities of adsorbent at an equilibrium time of $60 \mathrm{~min}$ at $22 \pm 3{ }^{\circ} \mathrm{C}$. At the end of each adsorption trial, the slurry was vacuum filtered using Whatman GE \# 5 $2.5 \mu \mathrm{m}$ grade filter paper. No adsorption of the tested organic pollutants in the filter was found in blank assays in the absence of adsorbent. The initial and final concentrations of TCA, TFA, HPA, tyrosol and phenol in solutions were determined via absorbance measured using a UV-Vis Spectrometer (Shimadzu UV-2600) at $\lambda_{\max }$ of $232,260,275,275$ and $275 \mathrm{~nm}$, respectively. Since adsorption is a separation technology, the adsorbate compounds should not undergo any transformation and hence the concentrations determined by UV-Vis 
absorbance analysis are accurate and were validated by HPLC using condition 1 .

\subsection{Electrochemical regeneration}

In order to assess the electrochemical regeneration of GNPs, consecutive steps involved adsorption, followed by electrochemical regeneration and re-adsorption with a fresh contaminated solution. The first adsorption step was performed as explained above, and the cake retained in the filter was electrochemically regenerated. This electrochemical regeneration was performed in a simple electrochemical cell. The filter paper supporting the adsorbent cake acted as a separation membrane, being put on top of a stainless steel 314 plate cathode, whereas the upper side of the cake was in contact with a $3 \mathrm{~mm}$ thick graphite plate anode. A volume of $2 \mathrm{~mL}$ of $2 \% \mathrm{NaCl}$ solution was added as electrolyte. To retain the adsorbent particles during the electrolysis, a ring of polycarbonate with $38.5 \mathrm{~mm}$ inner diameter and $4 \mathrm{~mm}$ height was used, thus the geometric area of the electrodes was $10 \mathrm{~cm}^{2}$. The electrochemical regeneration assays were made at constant current density $(j)$ provided by a potentiostat/galvanostat, which also monitored the cell voltage. Once regenerated, the adsorbent was reused to treat a fresh solution of the organic pollutant with the same composition as that used in the first adsorption step, for $60 \mathrm{~min}$. To avoid the interference of breakdown by-products formed during electrolysis, the initial and final concentrations of the pollutant after regeneration were determined by reversed-phase high-performance liquid chromatography (HPLC) (condition 1, as described in the Supplementary Material). The chromatograms exhibited peaks at retention times of 4.11, 3.89, 3.88, 3.91 and $4.05 \mathrm{~min}$ for TCA, TFA, HPA, tyrosol and phenol, respectively.

The adsorption assays and electrochemical regeneration of graphene were made in triplicate and average values are reported along with standard deviations. The percentage of regeneration efficiency was calculated as:

$$
\% \text { Regeneration efficiency }=\frac{q_{r}}{q_{i}} \times 100
$$

where $q_{\mathrm{r}}$ is the loading capacity measured at equilibrium after re-adsorption with regenerated adsorbent, and $q_{\mathrm{i}}$ is the initial adsorbate loading at equilibrium.

\subsection{Electrochemical degradation assays}

The EO- $\mathrm{H}_{2} \mathrm{O}_{2}$, EF and PEF treatments of tyrosol solutions were studied in two aqueous matrices corresponding to non-chlorinated $\left(15 \mathrm{mM} \quad \mathrm{Na}_{2} \mathrm{SO}_{4}+0.01 \mathrm{mM} \quad \mathrm{NaNO}_{3}\right)$ and chlorinated $(1 \mathrm{mM}$ $\mathrm{KCl}+12 \mathrm{mM} \mathrm{Na}_{2} \mathrm{SO}_{4}+0.01 \mathrm{mM} \mathrm{NaNO}$ ) media at $\mathrm{pH} 3.0$ with the same conductivity (about $3.5 \mathrm{mS} \mathrm{cm}^{-1}$ ). The latter matrix was chosen for mimicking the electrolyte composition of an actual OOMW (Flores et al., 2018). The cell was an open, undivided stirred tank reactor with a $100 \mathrm{~mL}$ solution kept at $35^{\circ} \mathrm{C}$ composed of a $3 \mathrm{~cm}^{2} \mathrm{BDD}$ anode and a $3 \mathrm{~cm}^{2}$ carbon-PTFE air-diffusion cathode for $\mathrm{H}_{2} \mathrm{O}_{2}$ electrogeneration, whose characteristics are reported in Flores et al. (2017a). A constant current density $(j)$ was applied and the cell voltage was monitored using a multimeter. $\mathrm{Fe}^{2+}$ was added to the solution at a concentration of $0.50 \mathrm{mM}$ in the EF and PEF trials, and the liquid phase was illuminated with a Philips TL/6W/08 fluorescent black light blue with $\lambda_{\text {max }}=360 \mathrm{~nm}$ in PEF.

Tyrosol concentration was determined by analyzing the initial and treated solutions through reversed-phase HPLC (condition 1, see Supplementary Material). In the case of EF and PEF, acetonitrile was immediately added to fresh samples to quench the degradation process. Final carboxylic acids were detected by ion-exclusion HPLC (condition 2, see Supplementary Material). The recorded chromatograms showed only the presence of oxalic acid at a retention time of $6.90 \mathrm{~min}$

\subsection{Measurements and analysis}

The electrochemical regeneration assays were made at constant $j$ provided by an EG\&G Princeton Applied Research 363 potentiostat/ galvanostat, which also monitored the cell voltage. Additionally, a Demestres 601BR digital multimeter was used to monitor the cell voltage. UV-Vis Shimadzu UV-2600 spectrometer was used to determine the initial and final concentrations of contaminants, i.e., TCA, TFA, HPA, tyrosol, and phenol at $\lambda_{\max }$ of $232,260,275,275$ and $275 \mathrm{~nm}$, respectively, at $25^{\circ} \mathrm{C}$.

The surface morphology of the GNPs before and after tyrosol loading and electrochemical regeneration were observed using transmission electron microscopy (TEM) (JEOL JEM-2100 LaB6 microscope) monitored at $200 \mathrm{kV}$ acceleration voltage, with a standard single-tilt holder. HPLC analysis was performed to monitor the concentration of contaminants (see details in Supplementary Material).

The TOC of solutions was measured after filtration of samples with Whatman $0.45 \mu \mathrm{m}$ PTFE filters, followed by direct injection into a Shimadzu VCSN TOC analyzer, with $\pm 1 \%$ accuracy. Details of the method to calculate the mineralization current efficiency (MCE, in \%) and the specific energy consumption per unit TOC mass $\left(\mathrm{EC}_{\mathrm{TOC}}\right.$ or

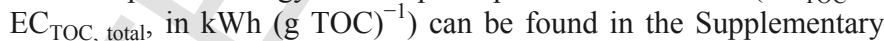
Material (Flox et al., 2007; Thiam et al., 2015a, b).

\section{Results and discussion \\ 3.1. Tyrosol adsorption}

Tyrosol adsorption on GNPs and GIC is shown in Fig. SM-2. Although the amount of GIC was an order of magnitude larger than that of GNPs, the former still exhibits a much lower tyrosol removal. The percentage removal after $60 \mathrm{~min}$ reached nearly a constant value of $14.2 \%$, whereas with GNPs the percentage removal reached a value of $72.2 \%$ and slightly increased to reach a limiting value of about $74.1 \%$ after $3 \mathrm{~h}$. The low removal rate obtained when GIC was used as the adsorbent may be due to the lower specific surface area, whereas the better performance of GNPs may be due to its higher specific surface area. Moreover, the result also indicates that both adsorbents achieved only partial removal of tyrosol under the applied experimental conditions.

The most widely used models to characterize the adsorption behavior are Langmuir and Freundlich (Dabrowski et al., 2005). The data indicate that the adsorption isotherm fits the Freundlich model more effectively than the Langmuir model (see Supporting Materials, Fig. SM-3), thus suggesting the occurrence of a homogeneous multilayer adsorption. Freundlich isotherm parameters calculated from the fitted experimental data yielded a value of $K_{\mathrm{f}}$ of about $1.22 \mathrm{mg} \mathrm{g}^{-1}(\mathrm{mg}$ $\left.\mathrm{L}^{-1}\right)^{-1 / n}$ and a slope $(1 / n)$ of about 0.55 , characteristic of a chemisorption process (de Sá et al., 2017).

\subsection{Electrochemical regeneration}

An effective adsorption process should be accompanied with a cost-effective regeneration procedure. In this study, the adsorbent at this stage will act as a concentrator of contaminant (tyrosol) and the regeneration process will destroy the contaminant without altering the 
property of the adsorbent (Berenguer et al., 2010). Regeneration of GNPs loaded with tyrosol was performed electrochemically. The process used has previously been reported for regeneration of various type of adsorbents, including GIC (Ashgar et al., 2012), and graphene-magnetite composites (Sharif et al., 2017). In this work, applying a constant current $\left(5 \mathrm{~mA} \mathrm{~cm}^{-2}\right)$ to a bed of tyrosol-loaded GNPs was used to regenerate the adsorbent and destroy the contaminant via electro-oxidation.

The impact of the amount of charge passed during the regeneration (expressed as charge loading per $\mathrm{g}$ of adsorbent) on the performance of the electrochemical regeneration is shown in Fig. 1a. A maximum regeneration efficiency of $75.7 \%$ was reached after $60 \mathrm{~min}$, corresponding to a charge loading of about $36 \mathrm{Cg}^{-1}$. The passage of
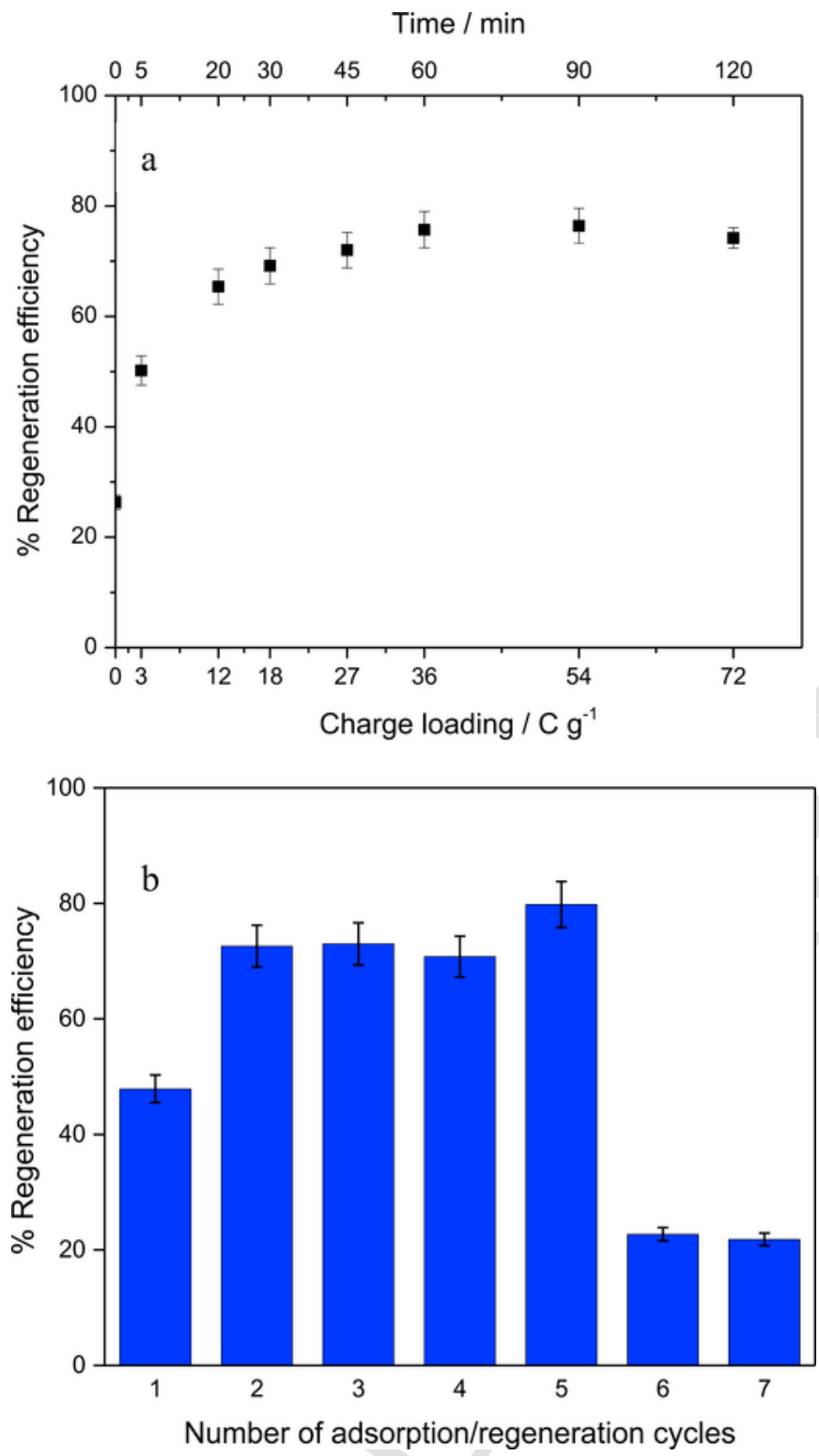

Fig. 1. (a) Regeneration efficiency of graphene vs. time and charge loading. Preliminary adsorption step was made with a suspension of $100 \mathrm{~mL}$ with $100 \mathrm{mg} \mathrm{L}-1$ tyrosol at $\mathrm{pH}=7.5$ and $5 \mathrm{~g} \mathrm{~L}-1$ graphene as adsorbent under stirring $(164 \mathrm{rpm})$ for $60 \mathrm{~min}$ at $22 \pm 3{ }^{\circ} \mathrm{C}$. (b) Variation of the regeneration efficiency of graphene with the number of consecutive adsorption/regeneration cycles, applying $5 \mathrm{~mA} \mathrm{~cm}-2$ for $30 \mathrm{~min}$ (charge of $90 \mathrm{C}$, i.e., $18 \mathrm{C} \mathrm{g}-1)$ during the electrochemical regeneration step. further electrical charge showed no improvement in regeneration efficiency. The regeneration efficiency shows nearly a constant value of around $75 \%$ with increasing charge loading up to $72 \mathrm{Cg}^{-1}$, indicating that the applied regeneration procedure was notable to achieve a complete regeneration $(100 \%)$.

The reusability of GNPs material following regeneration for several successive adsorption and electrochemical regeneration cycles was also evaluated. Based on the data shown in Fig. 1a, $30 \mathrm{~min} \mathrm{du}-$ ration $\left(18 \mathrm{Cg}^{-1}\right)$ was chosen for electrochemical regeneration at $5 \mathrm{~mA} \mathrm{~cm}^{-2}$ for the multiple cycle regeneration. The performance of successive adsorption/electrochemical regeneration cycles is summarized in Fig. 1b. The results indicate that, after the first regeneration process, the efficiency of the regeneration increased with increasing cycle time, and then collapse after 5 regeneration cycles. The regeneration efficiency increased from $48 \%$ in the first cycle to about $73 \%$ in the second regeneration cycle at the same applied electrochemical conditions. A similar behavior has been reported previously for regeneration of: (i) a graphene-magnetite composite loaded with Methylene Blue (Sharif et al., 2017), and (ii) GIC loaded with a range of different dyes (Ashgar et al., 2012). The increase in the regeneration efficiency may be due to the electro-oxidation of the adsorbed tyrosol as well as the GNPs material which may create active sites or functional groups leading to a greater adsorption capacity, and thus, regeneration efficiency. After further regeneration cycles, the efficiency increased to around $80 \%$ in the fifth cycle, but then reduced dramatically in the sixth cycle to reach a very low regeneration efficiency of only $23 \%$. During regeneration, although the electrochemical process increases the active adsorption sites, which is beneficial to increase the adsorption capacity, it may also enhance the electro-agglomeration of the remaining tyrosol. This may contribute to the collapse of the adsorption capacity of the GNPs.

The morphology of the GNPs loaded with tyrosol, prior and after first electrochemical regeneration cycle, was also investigated using TEM imaging technique and compared with the pristine GNPs in Fig. 2. The TEM image of the pristine GNPs (Fig. 2a) shows the typical smooth GNPs sheets, whereas GNPs loaded with tyrosol (Fig. 2b) clearly exhibited a uniform distribution of dark spots all over GNP sheets. This indicates the occurrence of adsorption of tyrosol on the GNPs material. In comparison, a TEM image following one regeneration cycle (Fig. 2c) exhibited a porous structure of the GNPs, which may be formed as a result of electro-oxidation of the GNPs surface, probably suggesting corrosion of the GNPs. These results are in agreement with our earlier observation of surface corrosion when an attempt was made to electrochemically regenerate GIC and GNPs (Ashgar et al., 2012). In addition, black spots remain on the surface of the electrochemically regenerated graphene, suggesting that tyrosol or its breakdown products remain on the graphene surface.

\subsection{Adsorption and electrochemical regeneration for treatment of OMWW contaminants}

In order to investigate the application of adsorption on GNPs to treat OMWW, the adsorption/electrochemical regeneration was performed for other aromatic contaminants that may coexist with tyrosol, namely; TCA, TFA, HPA, and phenol. In general, the percentage of removal of contaminants with GNPs showed the following trend: TFA $>$ TCA $>$ tyrosol $>$ HPA $>$ phenol (Fig. SM-4). For example, after 3 min of contact time, the percentage removal of the contaminants was $86.8 \%$ TFA, $80.3 \%$ TCA, $57.6 \%$ tyrosol, $49.8 \%$ HPA and $35.4 \%$ phenol. These removal values increased slightly with increased contact time, however, it only reaches a near complete removal for TFA (99.5\%) and TCA (96.3\%) after $24 \mathrm{~h}$. 

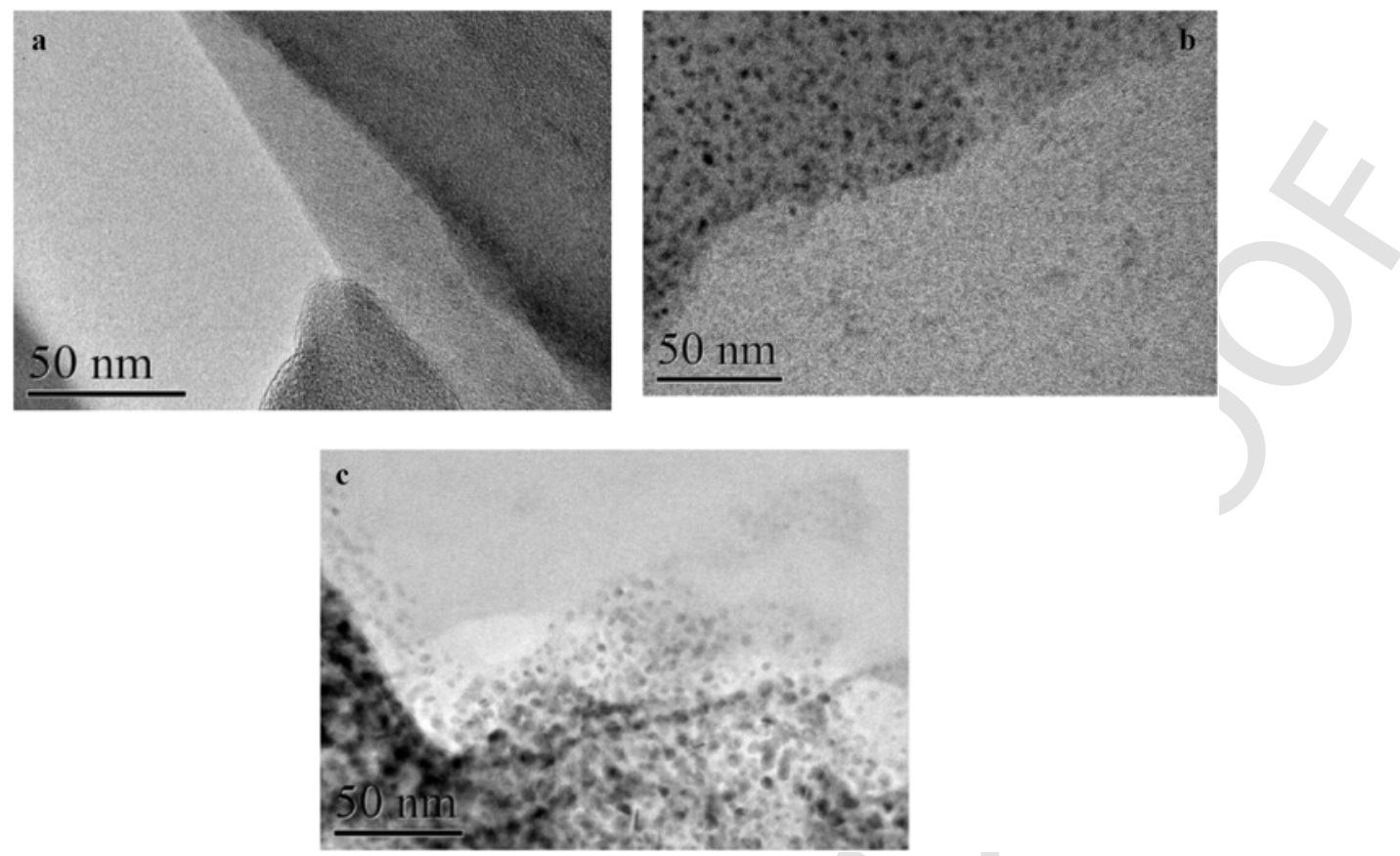

Fig. 2. TEM images of (a) pristine GNPs, (b) GNPs following first adsorption cycle of tyrosol and (c) GNPs following first adsorption/electrochemical regeneration cycle.

Fig. 3 shows the adsorption isotherms for these contaminants on graphene. Linear regression was used to fit the adsorption data of all adsorbates to the Freundlich model, and the isotherm parameters can be found in Table SM-1.

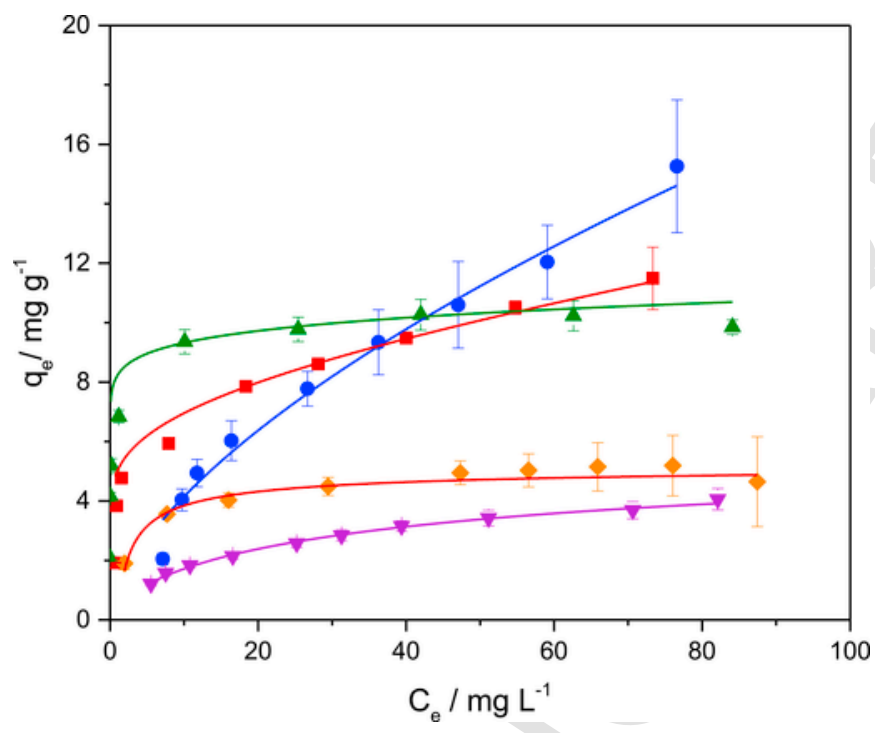

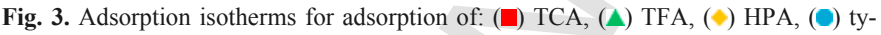
rosol and $(\nabla)$ phenol. The lines shown the Freundlich isotherm fitted to the data by linear regression. The equilibrium time of the isotherm was set after $60 \mathrm{~min}$ for $100 \mathrm{mg} \mathrm{L}^{-1}$ adsorbate on $10 \mathrm{gL}^{-1}$ GNPs at room temperature. Adsorption of organic molecules on GNPs is caused by net attractive forces involving the solute, solvent, and the adsorbent. Unlike in gas or vapor adsorption, in which van der Waals attraction is the dominant force to drive adsorption, the adsorption in liquid may be via dipole-dipole, induced-dipole, and hydrogen-bonding donor-acceptor interactions (Yang and Xing, 2010). These intermolecular forces are especially important when adsorption involves chemicals with the functional groups present on the compounds being studied here.
Adsorption interactions of hydrophobic nanomaterials, such as GNPs, in aqueous media can be classified as hydrophobic effects, $\pi-\pi$ bonds, hydrogen bonds, covalent, and electrostatic interactions (Yang and Xing, 2010). Based on the structure of the five compounds (including tyrosol), and from the adsorption capacity (Fig. SM-4), a number of conclusions can be drawn. The adsorption capacity of the acidic compounds is much higher than those of the other compounds. This explains the formation of donor-acceptor complexes between the $\pi-\pi$ bonds on the graphene rings (electron donor) and the aromatic ring of the adsorbates (electron acceptor). These results are in agreement with observation found by Richard et al. (2010), indicating that the presence of carboxylate groups (electron withdrawing) on the aromatic ring tends to lower its electronic density and enhance the aromatic ring to act as Lewis acid and thus increase the adsorption capacity. The presence of hydroxy group in the phenol ring, on the other hand, is known to delocalize electrons on the aromatic ring to act as Lewis base. The presence of methoxy group in the phenolic ring (TFA) can act upon the electron pair on the conjugate base to enhance the electron withdrawing property of the aromatic ring. At this stage, it is not possible to establish a relationship between electron distribution, Lewis acid or base and the adsorption behavior based on these tested compounds, but it appears that the more the electron withdrawing groups on the aromatic ring, one could expect a higher adsorption affinity on the GNP adsorbent.

To study the stability of the adsorption process and the possible reuse of GNPs after adsorption, electrochemical regeneration experiments were performed for each of the aromatic contaminants. The effect of the duration of regeneration process on the efficiency of electrochemical regeneration was investigated. As shown in Fig. 4, the efficiency of electrochemical regeneration following $2 \mathrm{~h}$ electrolysis was $89.6 \%, 81.7 \%, 42.8 \%$ and $25.3 \%$ for GNPs loaded with phenol, TFA, HPA and TCA, respectively. The regeneration efficiencies followed a different trend to the adsorption performance, with the contaminant with the lowest adsorption capacity (phenol) achieving the highest regeneration efficiency. 


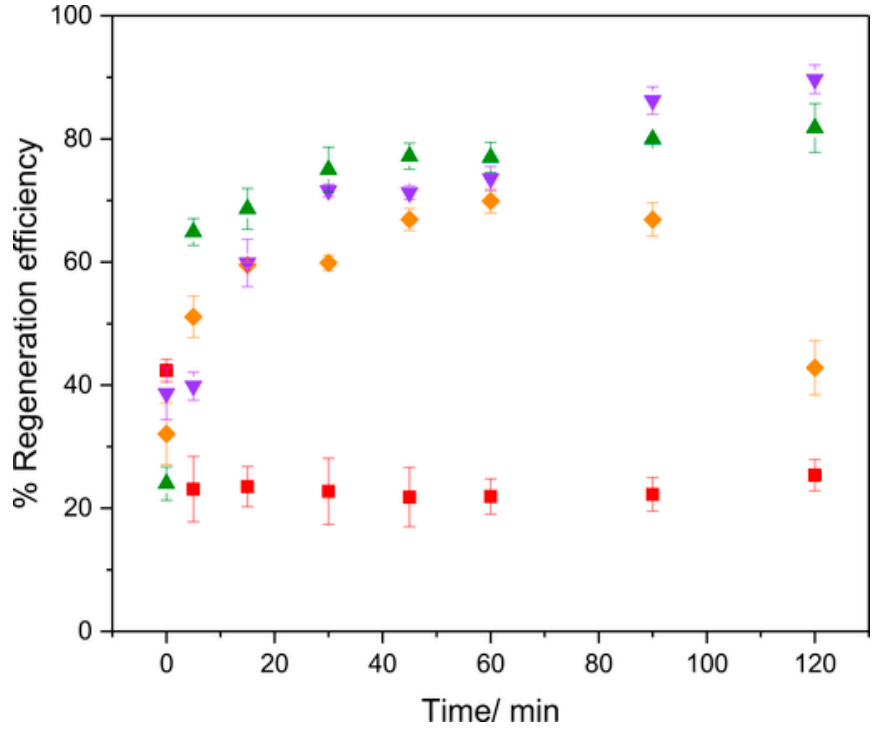

Fig. 4. Effect of regeneration time on regeneration efficiency of graphene for ( $\square$ ) TCA

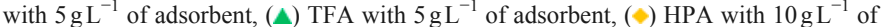
adsorbent and $(\nabla)$ phenol with $15 \mathrm{gL}^{-1}$ of adsorbent, $100 \mathrm{mgL}^{-1}$ of pollutant and at a current density of $5 \mathrm{~mA} \mathrm{~cm}{ }^{-2}$.

The specific energy consumption (per kilogram of contaminant) was determined for electrochemical regeneration of each contaminant (Table SM-2). The data show that the specific energy consumption after $60 \mathrm{~min}$ regeneration decreased in the following order: TCA $(108.5 \mathrm{kWh})>$ tyrosol $\quad(35.6 \mathrm{kWh})>$ phenol $\quad(35.1 \mathrm{kWh})>$ HPA $(29.7 \mathrm{kWh})>$ TFA $(21.9 \mathrm{kWh})$.

\subsection{Electrochemical treatment of tyrosol solutions}

EO- $\mathrm{H}_{2} \mathrm{O}_{2}$, EF and PEF treatments of $100 \mathrm{~mL}$ of $0.723 \mathrm{mM}$ tyrosol solution at $\mathrm{pH} 3.0$ were carried out with a $\mathrm{BDD} /$ air-diffusion cell at $j=30 \mathrm{~mA} \mathrm{~cm}^{-2}$ for $360 \mathrm{~min}$. EF and PEF trials were made with $0.50 \mathrm{mM} \mathrm{Fe}^{2+}$ as a homogeneous Fenton catalyst, and experiments were carried out in the presence and absence of chloride.

The tyrosol concentration during the $\mathrm{EO}-\mathrm{H}_{2} \mathrm{O}_{2}$ and PEF treatment is shown in Fig. 5a. Data for EF are not shown as they overlapped with those of PEF. A slow abatement was observed in $\mathrm{EO}-\mathrm{H}_{2} \mathrm{O}_{2}$ in both media, with $59.9 \%$ of tyrosol removed in the absence of chloride at $360 \mathrm{~min}$, increasing up to $79.5 \%$ in the chlorinated matrix. A much faster decay was obtained in the EF and PEF experiments, with the tyrosol removal approaching $100 \%$ after $60-70 \mathrm{~min}$. The inset panel of Fig. 5a shows the good agreement with a pseudo-first-order kinetics at short times for all these experiments. Apparent rate constants of 0.0095 and $0.013 \mathrm{~min}^{-1}$ were obtained in $\mathrm{EO}-\mathrm{H}_{2} \mathrm{O}_{2}$ in non-chlorinated and chlorinated media, respectively. The apparent rate constants for the PEF treatment were 0.063 and $0.090 \mathrm{~min}^{-1}$ in non-chlorinated and chlorinated media, respectively.

The slow decay of tyrosol by $\mathrm{EO}-\mathrm{H}_{2} \mathrm{O}_{2}$ can be related to its low reactivity with $\operatorname{BDD}(\mathrm{OH})$ formed from reaction (1). The slight increase in removal in the presence of chloride may be associated with the generation of active chlorine $\left(\mathrm{Cl}_{2} / \mathrm{HClO}\right)$ from the anodic $\mathrm{Cl}^{-}$ oxidation (Donaldson et al., 2002; Sirés et al., 2014; Thiam et al., 2015b). Our results indicate that the decontamination performance of active chlrine and $\operatorname{BDD}(\mathrm{OH})$ are quite similar, but much lower than that of $\mathrm{OH}$ formed in the bulk in PEF and EF. In these latter processes, the presence of $\mathrm{Cl}^{-}$led to a slight decrease in performance, probably due to the reaction of $\mathrm{Cl}^{-}$with $\mathrm{OH}$, along with the oxida-
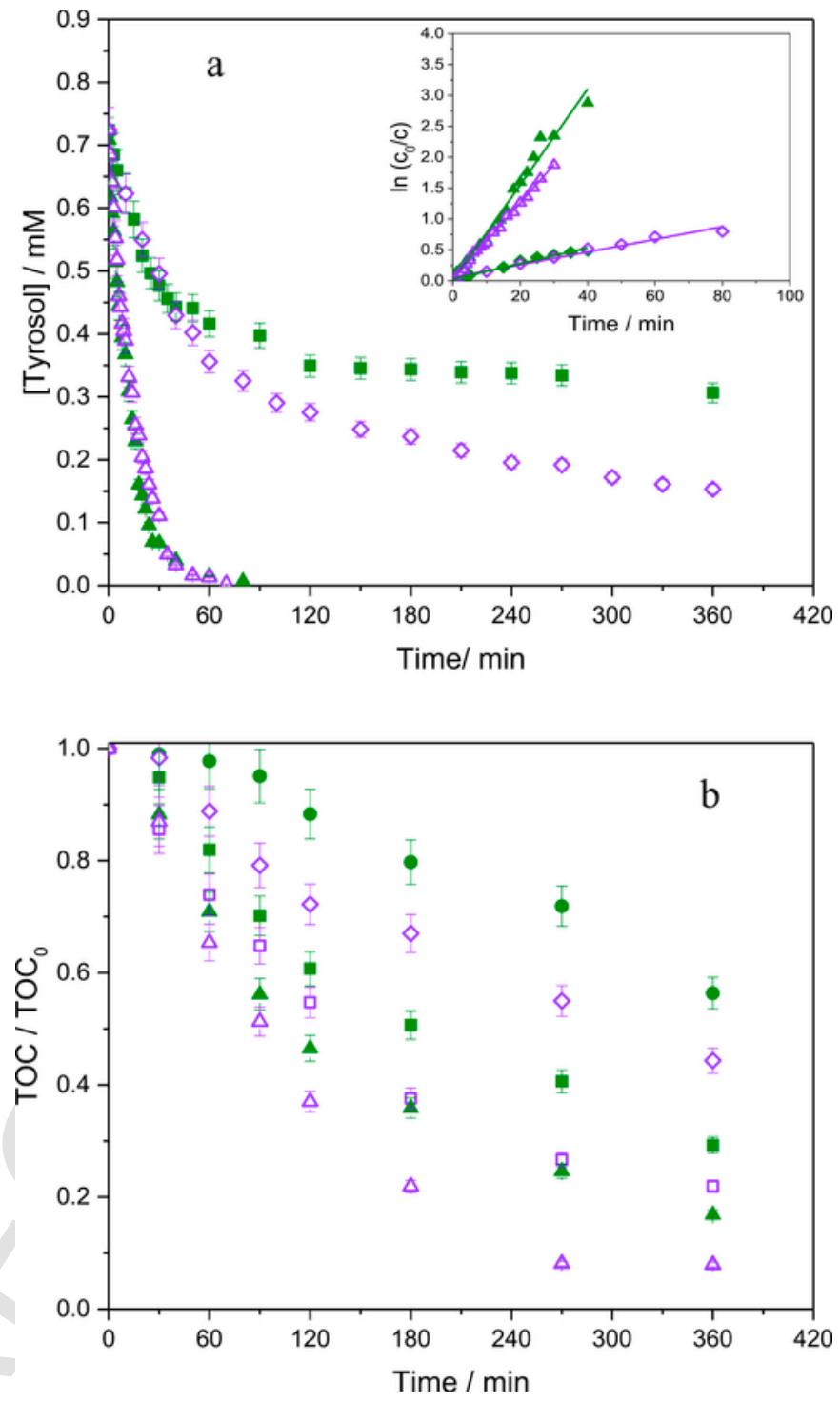

Fig. 5. Decay of (a) tyrosol concentration and (b) normalized TOC with electrolysis time during the electrochemical degradation of $150 \mathrm{~mL}$ of a $0.723 \mathrm{mM}$ substrate solution in $(\bullet, \boldsymbol{\bullet}, \Delta) 15 \mathrm{mM} \mathrm{Na}_{2} \mathrm{SO}_{4}+0.01 \mathrm{mM} \mathrm{NaNO}_{3}$ and $(\odot, \square, \triangle) 1 \mathrm{mM} \mathrm{KCl}+12 \mathrm{mM}$ $\mathrm{Na}_{2} \mathrm{SO}_{4}+0.01 \mathrm{mM} \mathrm{NaNO}$ at $\mathrm{pH} 3.0$ and $25^{\circ} \mathrm{C}$ using a BDD/air-diffusion cell (electrodes of $3 \mathrm{~cm}^{2}$ geometric area) at $30 \mathrm{~mA} \mathrm{~cm}^{-2}$. Method: $(\bullet, \circ) \mathrm{EO}-\mathrm{H}_{2} \mathrm{O}_{2},(\square, \square)$ EF with $0.50 \mathrm{mM} \mathrm{Fe}^{2+}$ and $(\Delta, \triangle)$ PEF with $0.50 \mathrm{mM} \mathrm{Fe}^{2+}$ under a 6-W UVA light irradiation. The inset in (a) presents the corresponding pseudo-first-order kinetic analysis of the concentration abatement.

tion of $\mathrm{H}_{2} \mathrm{O}_{2}$ by active chlorine (Thiam et al., 2015b; Yasri et al., 2015).

Based on TOC concentrations, the oxidation power of the EAOPs increased in the order: $\mathrm{EO}-\mathrm{H}_{2} \mathrm{O}_{2}<\mathrm{EF}<\mathrm{PEF}$, with greater mineralization in the presence of chloride in all cases (Fig. 5b). These findings suggest that chlorinated derivatives originater from $\mathrm{HClO}$ are more easily mineralized with $\mathrm{BDD}(\mathrm{OH})$ and/or ${ }^{\circ} \mathrm{OH}$ in $\mathrm{EO}-\mathrm{H}_{2} \mathrm{O}_{2}$ and $\mathrm{EF}$ as compared to non-chlorinated products. The superiority of $\mathrm{PEF}$ is related to the additional photolysis of photoactive intermediates, which became more significant in the presence of chloride. Fig. 5b shows that for the PEF process with chloride, TOC was reduced by $93.5 \%$ after $270 \mathrm{~min}$ of electrolysis, without further improvement at longer time. This means that a small amount $(6.5 \%$ of the initial TOC) of very recalcitrant products cannot be removed by 
$\mathrm{BDD}\left({ }^{\circ} \mathrm{OH}\right),{ }^{\circ} \mathrm{OH}, \mathrm{HClO}$ and UVA radiation and remains in the final solution, even after the powerful PEF treatment.

The mineralization current efficiency increased with increasing oxidation power of the treatment (Fig. SM-5a and Table 1). For PEF in the presence of chloride, a maximum current efficiency of $42.2 \%$ was obtained at $60 \mathrm{~min}$, before it decayed gradually to $18.7 \%$. This drop is presumably associated with the increasing proportion of recalcitrant contaminants and the decrease in the concentration of organics (Sirés et al., 2014; Coria et al., 2016). This trend was observed in EF and $\mathrm{PEF}$ as the organic species are rapidly destroyed by ${ }^{\circ} \mathrm{OH}, \mathrm{HClO}$ and/ or UVA light. However, it was less evident in EO- $\mathrm{H}_{2} \mathrm{O}_{2}$ treatments, especially in the absence of chloride, where the lowest current efficiency values, between $7.1 \%$ and $8.8 \%$ after $120 \mathrm{~min}$, were ohtained, suggesting a constant mineralization rate upon action of $\operatorname{BDD}(\mathrm{OH})$.

The lowest energy consumption obtained was $0.79 \mathrm{kWh}(\mathrm{g} \text { TOC })^{-1}$ for the most powerful treatment, PEF in the presence of chloride, whereas the highest value of $1.95 \mathrm{kWh}\left(\mathrm{g}\right.$ TOC) ${ }^{-1}$ was obtained in EO- $\mathrm{H}_{2} \mathrm{O}_{2}$ in the absence of chloride (Fig. SM-5b and Table 1).

When the energy power of the 6-W UVA lamp was taken into account in the PEF process, the $\mathrm{EC}_{\mathrm{TOC}}$, total values increased dramatically, up to 5.1-5.8-fold compared to the corresponding $\mathrm{EC}_{\mathrm{TOC}}$ ones. This suggests that the PEF treatment would be economically viable if sunlight could be used to irradiate the solution.

Finally, the effect of $j$ within the range $10-30 \mathrm{mAcm}^{-2}$ on the degradation of $0.723 \mathrm{mM}$ tyrosol solutions was evaluated for the three EAOPs, and the effect of substrate concentration in the range

Table 1

Percentage of TOC removal, mineralization current efficiency and specific energy consumption per unit TOC mass for the degradation of $150 \mathrm{~mL}$ of tyrosol solutions in two aqueous matrices at $\mathrm{pH} 3.0$ using different EAOPs with a BDD/air-diffusion cell under selected conditions.

\begin{tabular}{|c|c|c|c|c|c|}
\hline Method & $\begin{array}{l}{[\text { Tyrosol }]_{0}} \\
(\mathrm{mM})\end{array}$ & $\begin{array}{l}\text { Current density } \\
\left(\mathrm{mA} \mathrm{cm}^{-2}\right)\end{array}$ & $\begin{array}{l}\% \text { TOC } \\
\text { removal }\end{array}$ & $\begin{array}{l}\% \\
\mathrm{MCE}\end{array}$ & $\begin{array}{l}\mathrm{EC}_{\mathrm{TOC}}(\mathrm{kWh}(\mathrm{g} \\
\left.\mathrm{TOC}^{-1}\right)\end{array}$ \\
\hline \multicolumn{6}{|c|}{$15 \mathrm{mM} \mathrm{Na}_{2} \mathrm{SO}_{4}+0.01 \mathrm{mM} \mathrm{NaNO}{ }_{3}$} \\
\hline \multirow[t]{2}{*}{$\begin{array}{l}\text { EO- } \\
\mathrm{H}_{2} \mathrm{O}_{2}\end{array}$} & 0.723 & 10 & 36.2 & 22.1 & 0.39 \\
\hline & 0.723 & 30 & 43.6 & 8.9 & 1.95 \\
\hline \multirow[t]{2}{*}{$\mathrm{EF}^{\mathrm{a}}$} & 0.723 & 10 & 63.3 & 38.6 & 0.20 \\
\hline & 0.723 & 30 & 70.7 & 14.4 & 1.21 \\
\hline \multirow[t]{2}{*}{$\mathrm{PEF}^{\mathrm{a}}$, } & 0.723 & 10 & 73.6 & 44.9 & $0.18(4.90)^{\mathrm{c}}$ \\
\hline & 0.723 & 30 & 83.2 & 16.9 & $1.02(5.20)^{\mathrm{c}}$ \\
\hline \multicolumn{6}{|c|}{$1 \mathrm{mM} \mathrm{KCl}+12 \mathrm{mM} \mathrm{Na}_{2} \mathrm{SO}_{4}+0.01 \mathrm{mM} \mathrm{NaNO}$} \\
\hline \multirow{6}{*}{$\begin{array}{l}\text { EO- } \\
\mathrm{H}_{2} \mathrm{O}_{2}\end{array}$} & 0.723 & 10 & 34.8 & 21.2 & 0.35 \\
\hline & 0.723 & 20 & 40.2 & 12.2 & 1.15 \\
\hline & 0.723 & 30 & 55.7 & 11.3 & 1.25 \\
\hline & 1.047 & 10 & 28.1 & 25.2 & 0.29 \\
\hline & 2.096 & 10 & 20.1 & 35.5 & 0.19 \\
\hline & 5.239 & 10 & 10.2 & 45.0 & 0.16 \\
\hline \multirow[t]{6}{*}{$\mathrm{EF}^{\mathrm{a}}$} & 0.723 & 10 & 68.0 & 41.5 & 0.18 \\
\hline & 0.723 & 20 & 69.2 & 21.2 & 0.60 \\
\hline & 0.723 & 30 & 78.1 & 15.9 & 1.15 \\
\hline & 1.047 & 10 & 48.3 & 49.0 & 0.17 \\
\hline & 2.096 & 10 & 34.8 & 61.5 & 0.14 \\
\hline & 5.239 & 10 & 11.3 & 49.9 & 0.14 \\
\hline \multirow[t]{6}{*}{$\mathrm{PEF}^{\mathrm{a}}$, } & 0.723 & 10 & 84.5 & 51.5 & $0.14(4.25)^{\mathrm{c}}$ \\
\hline & 0.723 & 20 & 93.3 & 28.5 & $0.43(4.16)^{\mathrm{c}}$ \\
\hline & 0.723 & 30 & 93.5 & 18.7 & $0.79(4.57)^{\mathrm{c}}$ \\
\hline & 1.047 & 10 & 62.2 & 55.0 & $0.13(3.98)^{\mathrm{c}}$ \\
\hline & 2.096 & 10 & 41.4 & 73.2 & $0.12(3.02)^{\mathrm{c}}$ \\
\hline & 5.239 & 10 & 14.7 & 65.1 & $0.13(3.39)^{\mathrm{c}}$ \\
\hline
\end{tabular}

${ }^{\text {a }}$ With $0.50 \mathrm{mM} \mathrm{Fe}^{2+}$

b With a 6-W UVA lamp.

${ }^{\mathbf{c}} \mathrm{EC}_{\mathrm{TOC} \text {, total }}$ calculated from Eq. (SM4).
$0.723-5.239 \mathrm{mMat} j=10 \mathrm{~mA} \mathrm{~cm}^{-2}$, was examined (Table 1). It was found that an increase in $j$ always led to higher TOC removal due to the larger production of oxidizing agents and enhanced generation of $\mathrm{H}_{2} \mathrm{O}_{2}$ (Sirés et al., 2014). Conversely, the corresponding current efficiency values showed a significant decrease, due to the increased rate of parasitic reactions (Thiam et al., 2015b). As expected, the energy consumption increased with current density, due to the increase in the cell voltage. The difference was not so significant when the $\mathrm{EC}_{\mathrm{TOC} \text {, total }}$ was calculated for PEF trials because of the high lamp power.

Although the percentage removal of TOC decreased as contaminant concentration increased, the total amount of TOC removed increased in most cases, as indicated by the increasing current efficiency. In EO- $\mathrm{H}_{2} \mathrm{O}_{2}$, this occurred for the range of concentrations tested, but for EF and PEF the current efficiency decreased when the tyrosol concentration was increased from 2.069 to $5.239 \mathrm{mM}$. This increase in current efficiency is expected due to the higher reactant concentration (Sirés et al., 2014). The drop in current efficiency in EF and $\mathrm{PEF}$ at high tyrosol concentration reveals a more significant role of parasitic reactions in the treatments. The most efficient PEF treatment was obtained for $2.069 \mathrm{mM}$ tyrosol, yielding a $41.4 \%$ TOC abatement, maximum current efficiency of $73.2 \%$ and a low energy consumption (Table 1).

\section{Conclusions}

The effectiveness of remediation process such as adsorption/electrochemical regeneration, electrochemical oxidation with $\mathrm{H}_{2} \mathrm{O}_{2}$, electro-Fenton and photoelectro-Fenton, was investigated using tyrosol solution as a model contaminant present in OMWW. The structure of the adsorbate plays a critical role for both adsorption and electrochemical regeneration. The complex bonding of GNPs as an electron donor with tyrosol as adsorbate limits the electrochemical regeneration to 5 cycles and hence the reusability of GNPs as an adsorbent was found to be limited. Contaminants such as TFA contain functional groups that are typically electron withdrawing. Hence, they act as Lewis acid with $\pi-\pi$ donor, and in this case GNPs were found to be more effective in terms of both adsorption capacity and electrochemical regeneration efficiency. PEF process was the most powerful EAOP for the degradation and mineralization of tyrosol solutions at $\mathrm{pH} 3.0$ in non-chlorinated and chlorinated matrices using a BDD/air-diffusion cell. This is due to the fast photolytic action of UVA radiation over the intermediates formed from the attack of the generated oxidizing agents. Tyrosol oxidation by $\mathrm{BDD}(\mathrm{OH})$ and/or $\mathrm{HC} 1 \mathrm{O}$ was poor in $\mathrm{EO}-\mathrm{H}_{2} \mathrm{O}_{2}$, but was enhanced by the parallel attack of ${ }^{\circ} \mathrm{OH}$ in the bulk in EF and PEF. Tyrosol decay was found to follow pseudo-first-order kinetics in all cases. In all the EAOPs, a more rapid mineralization was achieved in the presence of chloride, indicating that active chlorine played a significant role. An increase in current density and a decrease in substrate concentration led to higher TOC removal, lower current efficiency and larger specific energy consumptions.

\section{Acknowledgements}

The authors are grateful to the financial support from project CTQ2016-78616-R (AEI/FEDER EU), as well as to the PhD fellowship awarded to N. Flores (SENESCYT, Ecuador).

\section{Appendix A. Supplementary data}

Supplementary data related to this article can be found at https:// doi.org/10.1016/j.chemosphere.2018.03.028. 


\section{References}

Aliotta, G., Fiorentiono, A., Oliva, A., Temussi, F., 2002. Olive oil mill wastewater: isolation of polyphenols and their phytotoxicity in vitro. Allelopathy J. 9, 9-17.

Allouche, N., Fki, I., Sayadi, S., 2004. Toward a high yield recovery of antioxidants and purified hydroxytyrosol from olive mill wastewaters. J. Agric. Food Chem. 52, $267-273$

Ammar, S., Oturan, M.A., Labiadh, L., Guersalli, A., Abdelhedi, R., Oturan, N., Brillas, E., 2015. Degradation of tyrosol by a novel electro-Fenton process using pyrite as heterogeneous source of iron catalyst. Water Res. 74, 77-87.

Ashgar, H.M.A., Roberts, E.P.L., Hussain, S.N., Campen, A.K., Brown, N.W., 2012 Wastewater treatment by adsorption with electrochemical regeneration using graphite-based adsorbents. J. Appl. Electrochem. 42, 797-807.

Ben Abdallah, F., Hmani, E., Bouaziz, M., Jaziri, M., Abdelhedi, R., 2017. Recovery of hydroxytyrosol a high added value compound through tyrosol conversion by electro-Fenton process. Separ. Purif. Technol. 188, 260-265.

Berenguer, R., Marco-Lozar, J.P., Quijada, C., Cazorla-Amorós, D., Morallón, E., 2010. Comparison among chemical, thermal, and electrochemical regeneration of phenol-saturated activated carbon. Energy Fuels 24, 3366-3372.

Brown, N.W., Roberts, E.P.L., 2007. Electrochemical pre-treatment of effluents containing chlorinated compounds using an adsorbent. J. Appl. Electrochem. 37, $1329-1335$.

Brown, N.W., Roberts, E.P.L., Chasiotis, A., Cherdron, T., Sanghrajka, N., 2004a. Atrazine removal using adsorption and electrochemical regeneration. Water Res. 38, 3067-3074.

Brown, N.W., Roberts, E.P.L., Garforth, A.A., Dryfe, R.A.W., 2004b. Electrochemical regeneration of a carbon-based adsorbent loaded with crystal violet dye. Electrochim. Acta 49, 3269-3281.

Capasso, A., Evidente, A., Avolio, S., Solla, F., 1999. A highly convenient synthesis of hydroxytyrosol and its recovery from agricultural wastewaters. J. Agric. Food Chem. 47, 1745-1748.

Coria, G., Sirés, I., Brillas, E., Nava, J.L., 2016. Influence of the anode material on the degradation of naproxen by Fenton-based electrochemical processes. Chem. Eng. J. 304, 817-825

Dabrowski, A., Podkościelny, P., Hubicki, Z., Barczak, M., 2005. Adsorption of phenolic compounds by activated carbon - a critical review. Chemosphere 58 , $1049-1070$

de Sá, A., Abreu, A.S., Moura, I., Machado, A.V., 2017. Polymeric materials for metal sorption from hydric resources. Water Purif. 289-322.

DellaGreca, M., Previtera, L., Temussi, F., Zarrelli, A., 2004. Low-molecular-weight components of olive oil mill waste-waters. Phytochem. Anal. 15, 184-188.

Dermeche, S., Nadour, M., Larroche, C., Moulti-Mati, F., Michaud, P., 2013. Olive mill wastes: biochemical characterizations and valorization strategies. Process Biochem. 48, 1532-1552.

Donaldson, J.D., Grimes, S.M., Yasri, N.G., Wheals, B., Parrick, J., Errington, W.E., 2002. Anodic oxidation of the dye materials methylene blue, acid blue 25 , reactive blue 2 and reactive blue 15 and the characterisation of novel intermediate compounds in the anodic oxidation of methylene blue. J. Chem. Technol. Biotechnol. $77,756-760$.

El-Ghenymy, A., Oturan, N., Oturan, M.A., Garrido, J.A., Cabot, P.L., Centellas, F., Rodríguez, R.M., Brillas, E., 2013. Comparative electro-Fenton and UVA photoelectro-Fenton degradation of the antibiotic sulfanilamide using a stirred BDD air-diffusion tank reactor. Chem. Eng. J. 234, 115-123.

Ena, A., Pintucci, C., Carlozzi, P., 2012. The recovery of polyphenols from olive mill waste using two adsorbing vegetable matrices. J. Biotechnol. 157, 573-577.

Ersan, G., Apul, O.G., Perreault, F., Karanfil, T., 2017. Adsorption of organic contaminants by graphene nanosheets: a review. Water Res. 126, 385-398.

Feng, L., Van Hullebusch, E.D., Rodrigo, M.A., Esposito, G., Oturan, M.A., 2013. Removal of residual anti-inflammatory and analgesic pharmaceuticals from aqueous systems by electrochemical advanced oxidation processes. A review. Chem. Eng. J. 228, 944-964.

Fernández-Bolaños, J., Rodríguez, G., Rodríguez, R., Heredia, A., Guillén, R., Jiménez, A., 2002. Production in large quantities of highly purified hydroxytyroso from liquid-solid waste of two-phase olive oil processing or "Alperujo. J. Agric. Food Chem. 50, 6804-6811.

Fiorentino, A., Gentili, A., Isidori, A., Monaco, P., Nardelli, A., Parrella, A., Temussi, F., 2003. Environmental effects caused by olive mill wastewaters: toxicity comparison of low-molecular-weight phenol components. J. Agric. Food Chem. 51, $1005-1009$

Flores, N., Brillas, E., Centellas, F., Rodríguez, R.M., Cabot, P.L., Garrido, J.A., Sirés, L., 2018. Treatment of olive oil mill wastewater by single electrocoagulation with different electrodes and sequential electrocoagulation/electrochemical Fenton-based processes. J. Hazard Mater. 347, 58-66.

Flores, N., Cabot, P.L., Centellas, F., Garrido, J.A., Rodríguez, R.M., Brillas, E., Sirés, I., 2017a. 4-Hydroxyphenylacetic acid oxidation in sulfate and real olive oil mill wastewater by electrochemical advanced processes with a boron-doped diamond anode. J. Hazard Mater. 321, 566-575.

Flores, N., Sirés, I., Garrido, J.A., Centellas, F., Rodríguez, R.M., Cabot, P.L., Brillas, E., 2016. Degradation of trans-ferulic acid in acidic aqueous medium by anodic oxidation, electro-Fenton and photoelectro-Fenton. J. Hazard Mater. 319, 3-12.

Flores, N., Thiam, A., Rodríguez, R.M., Centellas, F., Cabot, P.L., Garrido, J.A., Brillas, E., Sirés, I., 2017b. Electrochemical destruction of trans-cinnamic acid by advanced oxidation processes: kinetics, mineralization and degradation route. Environ. Sci. Pollut. Res. 24, 6071-6082.

Flox, C., Garrido, J.A., Rodríguez, R.M., Cabot, P.L., Centellas, F., Arias, C., Brillas, E., 2007. Mineralization of herbicide mecoprop by photoelectro-Fenton with UVA and solar light. Catal. Today 129, 29-36.

Galia, A., Lanzalaco, S., Sabatino, M.A., Dispenza, C., Scialdone, O., Sirés, I., 2016. Crosslinking of poly(vinylpyrrolidone) activated by electrogenerated hydroxyl radicals: a first step towards a simple and cheap synthetic route of nanogel vectors. Electrochem. Commun. 62, 64-68.

Gargouri, B., Gargouri, O.D., Khmakhem, I., Ammar, S., Abdelhedi, R., Bouaziz, M. 2017. Chemical composition and direct electrochemical oxidation of table olive processing wastewater using high oxidation power anodes. Chemosphere 166, 363-371.

Hussain, S.N., Roberts, E.P.L., Asghar, H.M.A., Campen, A.K., Brown, N.W., 2013. Oxidation of phenol and the adsorption of breakdown products using a graphite adsorbent with electrochemical regeneration. Electrochim. Acta 92, 20-30.

Justino, C.I.L., Pereira, R., Freitas, A.C., Rocha-Santos, T.A.P., Panteleitchouk, T.S.L., Duarte, A.C., 2012. Olive oil mill wastewaters before and after treatment: a critical review from the ecotoxicological point of view. Ecotoxicology 21, 615-629.

Khoufi, S., Aloui, F., Sayadi, S., 2008. Extraction of antioxidants from olive mill wastewater and electro-coagulation of exhausted fraction to reduce its toxicity on anaerobic digestion. J. Hazard Mater. 151, 531-539.

Magdich, S., Ben Ahmed, C., Jarboui, R., Ben Rouina, B., Boukhris, M., Ammar, E., 2013. Dose and frequency dependent effects of olive mill wastewater treatment on the chemical and microbial properties of soil. Chemosphere 93, 1896-1903.

Marselli, B., Garcia-Gomez, J., Michaud, P.-A., Rodrigo, M.A., Comninellis, Ch, 2003. Electrogeneration of hydroxyl radicals on boron-doped diamond electrodes. J. Electrochem. Soc. 150, D79-D83.

McNamara, C.J., Anastasiou, C.C., O'Flaherty, V., Mitchell, R., 2008. Bioremediation of olive mill wastewater. Int. Biodeterior. Biodegrad. 61, 127-134.

Moreira, F.C., Boaventura, R.A.R., Brillas, E., Vilar, V.J.P., 2017. Electrochemical advanced oxidation processes: a review on their application to synthetic and real wastewaters. Appl. Catal. B Environ. 202, 217-261.

Narbaitz, R.M., Cen, J.Q., 1994. Electrochemical regeneration of granular activated carbon. Water Res. 28, 1771-1778.

Nkrumah-Amoako, K., Roberts, E.P.L., Brown, N.W., Holmes, S.M., 2014. The effects of anodic treatment on the surface chemistry of a graphite intercalation compound. Electrochim. Acta $135,568-577$.

Ochando-Pulido, J.M., Victor-Ortega, M.D., Hodaifa, G., Martinez-Ferez, A., 2014. Physicochemical analysis and adequation of olive oil mill wastewater after advanced oxidation process for reclamation by pressure-driven membrane technology. Sci. Total Environ. 503-504, 113-121.

Olvera-Vargas, H., Oturan, N., Oturan, M.A., Brillas, E., 2015. Electro-Fenton and solar photoelectro-Fenton treatments of the pharmaceutical ranitidine in pre-pilot flow plant scale. Separ. Purif. Technol. 146, 127-135.

Panizza, M., Cerisola, G., 2009. Direct and mediated anodic oxidation of organic pollutants. Chem. Rev, 109, 6541-6569.

Richard, D., Delgado Núñez, M.L., Schweich, D., 2010. Adsorption of complex phenolic compounds on active charcoal: breakthrough curves. Chem. Eng. J. 158, 213-219.

Roig, A., Cayuela, M.L., Sánchez-Monedero, M.A., 2006. An overview on olive mil wastes and their valorisation methods. Waste Manag. 26, 960-969.

Sharif, F., Gagnon, L.R., Mulmi, S., Roberts, E.P.L., 2017. Electrochemical regeneration of a reduced graphene oxide/magnetite composite adsorbent loaded with methylene blue. Water Res. 114, 237-245.

Sirés, I., Brillas, E., Oturan, M.A., Rodrigo, M.A., Panizza, M., 2014. Electrochemical advanced oxidation processes: today and tomorrow. A review. Environ. Sci. Pollut. Res. 21, 8336-8367.

Steter, J.R., Brillas, E., Sirés, I., 2016. On the selection of the anode material for the electrochemical removal of methylparaben from different aqueous media. Electrochim. Acta 222, 1464-1474.

Thiam, A., Sirés, I., Garrido, J.A., Rodríguez, R.M., Brillas, E., 2015a. Effect of anions on electrochemical degradation of azo dye Carmoisine (Acid Red 14) using a BDD anode and air-diffusion cathode. Separ. Purif. Technol. 140, 43-52.

Thiam, A., Sirés, I., Garrido, J.A., Rodríguez, R.M., Brillas, E., 2015b. Decolorization and mineralization of Allura Red AC aqueous solutions by electrochemical advanced oxidation processes. J. Hazard Mater. 290, 34-42.

Vasudevan, S., Oturan, M.A., 2014. Electrochemistry: as cause and cure in water pollution-an overview. Environ. Chem. Lett. 12, 97-108. 
Wang, J., Tsuzuki, T., Tang, B., Hou, X., Sun, L., Wang, X., 2012. Reduced graphene oxide/ $\mathrm{ZnO}$ composite: reusable adsorbent for pollutant management. ACS Appl. Mater. Interfaces 4, 3084-3090.

Yang, K., Xing, B., 2010. Adsorption of organic compounds by carbon nanomaterials in aqueous phase: polanyi theory and its application. Chem. Rev. 110, 5989-6008.

Yasri, N.G., Gunasekaran, S., 2017. Electrochemical technologies for environmental remediation. In: In: Anjum, N.A., Gill, S.S., Tuteja, N. (Eds.), Enhancing Cleanup of Environmental Pollutants, vol. 2, Springer.
Yasri, N.G., Yaghmour, A., Gunasekaran, S., 2015. Effective removal of organics from corn wet milling steepwater effluent by electrochemical oxidation and adsorption on 3-D granulated graphite electrode. J. Environ. Chem. Eng 3, 930-937.

Yesilada, O., Sik, S., Sam, M., 1997. Biodegradation of olive oil mill wastewater by Coriolus versicolor and Funalia trogii: effects of agitation, initial COD concentration, inoculum size and immobilization. World J. Microbiol. Biotechnol. 14, $37-42$. 